\title{
A história oral na análise organizacional: a possível e promissora conversa entre a história e a administração
}

\section{Oral history in the organizational analysis: a possible and promising conversation between history and management}

\author{
Almiralva Ferraz Gomes ${ }^{1}$ \\ Weslei Gusmão Piau Santana ${ }^{2}$
}

\begin{abstract}
Resumo
Nos últimos anos tem se verificado um aumento do número de publicações em estudos organizacionais que adotam metodologias mais qualitativas que quantitativas. Este crescimento justifica-se pelo fato de os pesquisadores da área considerarem mais incisivamente o caráter multidisciplinar da administração como uma ciência social aplicada, que se utiliza de diversas fontes epistemológicas. Entretanto, os teóricos da Administração sempre relegaram, ou nunca consideraram, o potencial da História para a análise organizacional. Neste trabalho, propõe-se sensibilizar pesquisadores da área de Administração a respeito da potencialidade do diálogo entre a História e a Administração para a análise da realidade organizacional, bem como enfatizar a importância do desenvolvimento de estudos locais e regionais contemplando as vozes do "passado" e dos "esquecidos". Tendo em vista que as organizações somente serão satisfatoriamente compreendidas a partir do momento em que sua história é conhecida, apresentaremos, brevemente, neste artigo, a experiência da Universidade Estadual do Sudoeste da Bahia.
\end{abstract}

Palavras-chave: Administração; análise organizacional; História; História Oral; pesquisa qualitativa.

\begin{abstract}
In the last years the number of publications in organizational studies which adopt rather qualitative than quantitative methodologies has increased. This can be explained by the fact that researchers have been taking in account the multidisciplinary characteristics of business administration as an applied social science that makes use of several epistemological sources. However, scholars always relegated or never considered the potential of history studies for the analysis of organizations. The proposal of this work is not only to catch the researchers' eyes to the potentiality of the dialogue between history and administration as a tool to analyze the organizational reality, but emphasize the importance of the development of local and regional studies taking in account the voices from the "past" and of "forgotten people". Starting from the point of view that the organizations will only be understood satisfactorily when they know their own history, this article will present in brief the experience of the Universidade Estadual do Sudoeste da Bahia.
\end{abstract}

Key-words: Management; organizational analysis; History; Oral History; quality Research.

\footnotetext{
1 Mestre em Administração pela Universidade Federal da Bahia/UFBA, Doutoranda na Universidade Federal de Lavras/UFLA. Professora da Universidade Estadual do Sudoeste da Bahia. Endereço: Via Local A, 11 - Loteamento Bosque das Candeias - Candeias - Vitória da Conquista - Bahia - Brasil - CEP: 45055030. E-mail: almiralva@gmail.com

2 Doutorando em Administração na Universidade Federal da Bahia/UFBA. Mestre em Administração pela UFBA Professor Assistente da Universidade Estadual do Sudoeste da Bahia-UESB. Endereço: Rua Santos Dumont, 53 - São Vicente - Vitória da Conquista - Bahia - Brasil - CEP: 45010-230. E-mail: wpiau@hotmail.com
}

Artigo submetido em março de 2008 e aceito em março 2009 


\section{Introdução}

Alguns estudos no campo da Administração (BUFONI, 2002; CALDAS, TONELLI; LACOMBE, 2002; ROCHA; CERETTA, 1998) têm revelado um crescente interesse pela adoção de metodologias mais qualitativas que quantitativas. Este crescimento justifica-se pelo fato de os pesquisadores da área considerarem mais incisivamente o caráter multidisciplinar da Administração como uma Ciência Social Aplicada que se utiliza de diversas fontes epistemológicas, tais como a Sociologia, Antropologia, Ciência Política, Psicologia e Economia. Entretanto, de um modo geral, os teóricos da Administração sempre relegaram, ou ainda não consideraram, o potencial da História para a análise organizacional.

A História tem muito a contribuir para a Administração com recursos teóricos e metodológicos próprios que proporcionam o conhecimento de realidades organizacionais e administrativas contemporâneas por um novo viés: a história do tempo presente na narrativa dos sujeitos sociais (VIZEU, 2007; SALAMA, 1992). Além disso, o diálogo História-Administração pode trazer um novo olhar para os estudos organizacionais ao contemplar as "vozes" do "passado" ou dos "esquecidos".

A teoria organizacional, portanto, não pode dispensar o conhecimento histórico para a compreensão da realidade organizacional. A História pode ajudar a teoria administrativa a localizar-se temporalmente e entender por que se administra de um jeito e não de outro. Mediante essa conversação, pode-se analisar o presente administrativo de uma instituição, ouvir suas reivindicações, angústias, sugestões, críticas para melhor compreender sua vida organizacional contemporânea no contexto de sua realidade sócio-histórica.

Do seu início até praticamente a metade do século XIX, a História, herdeira da tradição positivista da epistemologia, via-se como ciência capaz de relatar o passado tal como este havia se dado, desde que anulada a subjetividade do historiador durante a pesquisa. A partir do século XIX, um movimento surgido nas universidades européias rompeu com essa visão ao criar o historicismo. Porém, a história historicista ainda é bastante presa a alguns métodos da Sociologia e tem como objeto, principalmente, a "grande história", isto é, a história dos grandes homens e dos estados. Contudo, a Escola dos Annales, na França, quebra este paradigma ao propor uma aliança da História com outras ciências, como a Sociologia, a Antropologia, a Filosofia e, principalmente, a Psicologia, individual e social.

Como tentativa de dar conta desta nova visão de documento, surge a História Oral. De acordo com Ichikawa e Santos (2003, p. 2), a História Oral é "uma história do tempo presente, pois implica uma percepção do passado como algo que tem continuidade hoje e cujo processo histórico não está acabado". É uma alternativa à história oficial, pois é capaz de captar experiências pessoais mantendo um compromisso com o contexto social.

Assim, tendo em vista a riqueza que se apresenta através do diálogo entre a História e a Administração, propõese, neste artigo, inicialmente, resgatar um pouco do percurso da historiografia, apresentar a História Oral como uma alternativa para a construção da História, discutir a ideia de memória e relacioná-la à História Oral e, consequentemente, à historiografia. Por fim, com base na experiência da Universidade Estadual do Sudoeste da Bahia, sugere-se o estreitamento dos laços entre a História e a Administração, entendendo que a primeira pode auxiliar como uma ferramenta para a análise organizacional.

\section{Historiografla: reflexões preliminares e um pouco de histórla}

Há pesquisadores que ainda mantêm vínculos com a tradição historiográfica do século XIX, que elegeu como modelo de documento histórico o testemunho escrito, objetivo (neutro), dado como fidedigno. Nessa perspectiva, os depoimentos passaram a ser considerados apenas fontes subsidiárias e de "baixo valor histórico", pois representariam um testemunho subjetivo, falível, cuja fidedignidade estaria comprometida por notícias tendenciosas, mentiras e calúnias que poderiam apresentar.

Se pouca credibilidade era dada aos depoimentos escritos, os orais foram praticamente ignorados. Neles se acentuariam aqueles aspectos negativos atribuídos a esse tipo de fonte, acrescidos da parca confiabilidade que a palavra falada assumia numa sociedade solidamente estabelecida sobre a escrita, e das dificuldades de 
preservação e divulgação, inerentes às fontes orais. Desse modo, como documento que deveria propiciar ao historiador o resgate dos acontecimentos, "tal como se sucederam", o testemunho oral ou escrito mostrava-se, evidentemente, uma fonte inadequada, só devendo ser utilizada como último recurso e, assim mesmo, com extrema cautela (BARBOZA, 2002; SARDE NETO, 2003; JOUTARD, 2005).

A maior contribuição para a mudança de paradigma foi o movimento iniciado por Marc Bloch e Lucien Febvre, com o lançamento da revista Annales, em 1929, tendo como objetivo explícito fazer dela um instrumento de enriquecimento da História, por sua aproximação com as ciências vizinhas e pelo incentivo à inovação temática. A atuação do grupo colaborou, portanto, para a construção da História como ciência e para a renovação dos seus estudos.

O "grupo dos Annales"3 tinha, no período de 1929 a 1969, concepções comuns que foram resultado de debates travados com historiadores tradicionais - positivistas e historicistas. As ideias e diretrizes do grupo, apresentadas por Burke (1997, p. 12-15), foram as seguintes:

a substituição da tradicional narrativa de acontecimentos por uma história-problema;

a história de todas as atividades humanas e não apenas da história política;

a colaboração com outras disciplinas, tais como a Geografia, a Sociologia, a Psicologia, a Economia, a Linguística e a Antropologia Social;

a introdução de diversos aspectos da vida social nos estudos da História: a vida diária, o povo e as coisas, bens que a humanidade produz ou consome, a civilização material, as representações coletivas, a história sociocultural;

a ênfase na história econômica, demográfica e social, salientando os aspectos sociais por meio de estudos regionais, coletivos e comparativos em detrimento do episódico e individual;

a descoberta e utilização de novas fontes: tradição oral e vestígios arqueológicos.

Esse movimento - chamado por Peter Burke de a "Revolução Francesa da historiografia" - revolucionou a História no que diz respeito a conceitos, abordagens e métodos. O grupo dos Annales passou a ser denominado, mais tarde, de "nova história", dedicando-se, sobretudo, à história do cotidiano e das mentalidades. Os historiadores desse grupo apontaram a necessidade de a História se dedicar menos aos acontecimentos, aos heróis e à cronologia dos fatos (BARBOZA, 2002; CALDAS, 2004; MARCOVITCH, 2005).

A história faz-se com documentos escritos, sem dúvida. Quando eles existem. Mas ela pode fazer-se, ela deve fazer-se sem documentos escritos, se os não houver. Com tudo o que o engenho do historiador pode permitir-lhe utilizar para fabricar o seu mel, à falta das flores habituais. Portanto, com palavras. Com signos. Com paisagens e telhas. Com formas de cultivo e ervas daninhas. Com eclipses da lua e cangas de bois. Com exames de pedras por geólogos e análises de espadas de metal por químicos. Numa palavra, com tudo aquilo que, pertencendo ao homem, depende do homem, serve o homem, exprime o homem, significa a presença, a atividade, os gostos e as maneiras de ser do homem. (FEBVRE, 1989, p. 249 apud BURKE, 1997)

\section{Histórla Oral: uma fonte (alternativa) de pesquisa para a construção da Histórla}

Apesar de não haver consenso entre aqueles que tratam da História Oral, faz-se necessário discutir o tema. Para alguns pesquisadores, nada mais é que uma técnica de investigação ou uma ciência auxiliar que está para a história do tempo presente assim como a arqueologia está para a história antiga. Para outros, ela vai além de um simples aperfeiçoamento técnico ou um requinte metodológico. Para François (2005), possui um potencial documental e heurístico que, desde que utilizado com conhecimento de causa, pode desembocar num verdadeiro salto qualitativo na construção da História.

\footnotetext{
${ }^{3}$ A Escola dos Annales é um movimento historiográfico assim chamado pelo periódico científico francês Annales d'histoire économique et sociale (posteriormente chamado Annales. Economies, sociétés, civilisations, e renomeado posteriormente em 1994 como Annales. Histoire, Sciences Sociales). A história da Escola dos Annales é mais conhecida por incorporar métodos das Ciências Sociais à História.
} 
Muita discussão, contudo, tem sido realizada a respeito do status da História Oral. Alguns argumentam que se trata de uma técnica; outros, de uma disciplina; e outros, ainda, de uma metodologia (AMADO; FERREIRA, 2005). Os defensores da História Oral como técnica interessam-se pelas experiências com gravações, transcrições e conservação de entrevistas e o aparato que as cerca. Aqueles que lhe atribuem um status de disciplina, baseiam-se em argumentos complexos e, às vezes, contraditórios. Todos, entretanto, parecem basear-se em uma idéia fundamental: a História Oral inaugurou técnicas específicas de pesquisa, procedimentos metodológicos singulares e um conjunto próprio de conceitos. Esse conjunto, por sua vez, norteia as duas outras instâncias, conferindo-lhes significado e emprestando unidade ao novo campo de conhecimento.

Amado e Ferreira (2005), por sua vez, são defensoras da História Oral como uma metodologia. As autoras não a reconhecem como uma área de estudos com objetivo próprio e capacidade de gerar, no seu interior, soluções teóricas para as questões surgidas na prática - assim, ela não poderia ser considerada uma disciplina. Em outras palavras, a História Oral, como todas as metodologias, apenas estabelece e ordena procedimentos de trabalho (AMADO; FERREIRA, 2005; ICHIKAWA; SANTOS, 2003).

Para Joutard (2005), a expressão "história oral" pode ser confundida com fonte oral, pois a primeira é ambígua e inexata. Assim, metodologicamente, ele e muitos pesquisadores da área preferem referir-se à fonte oral, pois entendem que é um tipo de fonte como tantas outras para a historiografia. Apesar da ressalva que Joutard (2005) faz à expressão "história oral", ele próprio admite que prefere "manter a expressão porque ela é simples e tem a antiguidade a seu favor" (p. 57).

Dessa forma, a História Oral pode ser compreendida como um método de pesquisa que utiliza a técnica da entrevista e outros procedimentos articulados entre si no registro de narrativas da experiência humana (THOMPSON, 1992; AMADO; FERREIRA, 2005; WALLOT apud JOUTARD, 2005). Deve-se ressaltar que, como técnica e fonte capaz de produzir conhecimento, a História Oral, modernamente, acaba também por utilizar-se de recursos eletrônicos.

Pela compreensão do que é história oral, vale lembrar que foram, sobretudo, os historiadores franceses que passaram a enfatizar o estudo do cotidiano, mostrando que as fontes da História não eram mais somente os documentos "oficiais". No Brasil, a maioria dos cientistas sociais ainda vê a fotografia, a caricatura, a carta, o diário, assim como o depoimento oral, como fontes subsidiárias, com baixo valor histórico, embora essas fontes sejam frequentemente utilizadas para ilustrar ou comprovar alguma ideia. Há aqueles que acreditam na História Oral, porém partindo do pressuposto de que o documento oral deve ser cruzado com outras fontes, de preferência escritas e oficiais.

Há também aqueles que, em suas dissertações, teses e ensaios, utilizam entrevistas como fonte de informação para preencher lacunas em suas pesquisas. Todavia, esses trabalhos não fazem nenhuma menção à História Oral e à produção acerca dessa metodologia disponível no país e, muito menos, indicam as metodologias de pesquisa utilizadas (ICHIKAWA; SANTOS, 2003).

Segundo a visão e prática daqueles historiadores que veem no documento escrito a condição sine qua non para a sua ciência, a África não teria história, pois esse continente é constituído de sociedades organizadas pela tradição unicamente oral. E as tribos indígenas brasileiras somente poderiam ser estudadas com base nos dados da Funai? A pesquisadores que defendem tal visão, pode-se replicar que todo documento é questionável e que todo documento escrito ou iconográfico é limitado e subjetivo.

Entretanto, as atuais correntes da historiografia têm ressaltado a necessidade de uma reavaliação dos critérios pelos quais se determinam a utilização e análise de fontes históricas, pois, na produção do conhecimento, fatores como a subjetividade e a seletividade são inevitáveis. Assim, a História Oral tem adquirido um novo status, devido aos novos significados atribuídos aos depoimentos, às histórias de vida, às biografias, etc. Vale salientar, contudo, que o documento gravado, como qualquer tipo de documento, está sujeito a diversas leituras.

O que também é interessante é a oportunidade que se tem de recuperar testemunhos relegados pela História, o que permite a documentação de pontos de vista diferentes ou opostos sobre o mesmo fato, os quais, omitidos ou desprezados pelo discurso do poder, estariam condenados ao esquecimento. Portanto, faz-se necessária uma 
revisão das posições historiográficas com relação às "novas" fontes históricas - sonora e visual -, esta última representada pela fotografia, caricatura e cinema. Um grande desafio para os atuais pesquisadores é vencer os limites livrescos e quebrar a resistência a novas fontes documentais, novas técnicas, linguagens e suportes. Apesar disso, no presente trabalho, não se defende o uso exclusivo de fontes orais, por acreditar-se que a utilização de diversas fontes será mais enriquecedora para a pesquisa, ou seja, permitirá uma miscelânea bastante interessante e enriquecedora.

Esse redimensionamento do trabalho do historiador e a crescente revalorização da oralidade - embora mediatizada - trazida pela expansão dos meios de comunicação de massa, como o rádio, a televisão, o cinema, discos, etc., indicam a oportunidade de revisão de um posicionamento historiográfico segundo o qual se tem, até hoje, olhado com grande desconfiança o testemunho pessoal.

Na busca de características de uma coletividade, a realização de depoimentos pessoais permite-nos captar, pelas reminiscências, o que as pessoas vivenciaram e experimentaram. As análises históricas são construídas com base em vestígios e/ou registros deixados pelas gerações anteriores. Entretanto, a produção dessa matéria-prima quase sempre esteve a cargo das classes dominantes e, até bem recentemente, tal fato não era posto em questão. A coleta de depoimentos e de histórias de vida pode ser inserida no amplo esforço de resgatar a palavra de indivíduos que, sem a mediação do pesquisador, não deixariam nenhum testemunho.

Assim, essa metodologia abre novas perspectivas para o entendimento do passado recente, pois amplifica vozes que não se fariam ouvir. Além de nos possibilitar o conhecimento de diferentes "versões" sobre determinado ponto, os depoimentos podem apontar continuidade, descontinuidade ou mesmo contradições no discurso do depoente.

A maior potencialidade desse tipo de fonte é a possibilidade de resgatar o indivíduo como sujeito no processo histórico. Consequentemente, reativa o conflito entre liberdade e determinismo ou entre estrutura social e ação humana. Os indivíduos, elementos fundamentais para a compreensão da vida humana, têm sido frequentemente minimizados e marginalizados pelo cientista social, que acredita que os documentos pessoais são subjetivos, descritivos e arbitrários para contribuírem com o avanço científico. Ou seja, a história do mundo tem sido escrita, fundamentalmente, na língua da racionalidade e da exatidão absolutas. A História Oral, contudo, privilegia, enfim, a voz dos indivíduos, não apenas dos grandes homens, como tem ocorrido, mas dá a palavra aos esquecidos ou "vencidos" da história. Como diz Benjamin (1985), qualquer um de nós pode ser uma personagem histórica ao narrarmos as experiências vividas por nós mesmos ou aquelas vividas por outros e a nós relatadas.

Quanto ao nosso mundo cotidiano, parece estar escrito mais num mosaico de línguas, como uma parede coberta de grafites, cheia de rabiscos sobrepostos, como um palimpsesto cujo pergaminho foi raspado e reescrito várias vezes, como uma colagem de Schwitter, uma combinação de alfabetos, citações heterogêneas, gírias e impressos de computador. (CALVINO, 2005, p. 145)

\section{Historiografla, Histórla Oral e memória}

O desenvolvimento deste trabalho leva inevitavelmente à busca da compreensão do conceito de memória. Este esforço se justifica pelo fato de que a História Oral tem como suporte as lembranças, o que evidencia uma memória coletiva. Esta última pode ser entendida como uma somatória de experiências individuais, passíveis de serem utilizadas como fontes históricas, ou seja, a memória é o vivido e a história é o elaborado. Com o resgate da memória se reconstrói o passado.

É preciso destacar que são poucas as tentativas de definição do que é memória, pois essa ainda não foi eleita especificamente objeto de estudo em áreas como a História, a Sociologia, a Antropologia etc. Embora visando interesse específico da área, alguns títulos são localizados na Biologia e, principalmente, na Psicologia.

Em decorrência da complexidade do assunto e da dificuldade de acesso a bibliografias que tratem do tema de forma mais abrangente, percorreu-se o caminho no sentido de buscar a acepção de memória para o senso comum na atualidade, resgatar a concepção e o significado de memória em diferentes momentos da história, da 
Antiguidade à atualidade, para, então, refletir sobre os fenômenos da memória individual, valendo-se de seus principais teóricos.

Expressões do tipo "memória de elefante", "memória visual", "lapso da memória" fazem parte de nosso universo vocabular. Em nosso cotidiano, há a noção de memória relacionada à ideia de que o Brasil é um país sem memória histórica. Na atualidade, a acepção da memória está ligada ao desenvolvimento da Cibernética memória armazenada pelos computadores - e, também, da Biologia - memória da hereditariedade, presente no código genético.

$\mathrm{Na}$ Antiguidade Clássica, os gregos fizeram da memória uma deusa, Mnemósine, que lembra aos homens os altos feitos dos heróis e também preside a poesia lírica. O poeta é, pois, um homem que, quando possuído pela memória, é transportado por ela ao coração dos acontecimentos antigos, tornando-se, assim, um adivinho do passado (BOSI, 1994). Aristóteles distingue mnemê (memória) - faculdade de conservar o passado - e mamnesi (reminiscência) - faculdade de evocar voluntariamente esse passado por um esforço intelectual. Platão, por sua vez, emprega a imagem da memória como impressão, traços depositados e gravados em nós (SMOLKA, 2000).

Segundo Le Goff (1984 apud BURKE, 1997), a memória na Idade Média passou por profundas transformações em decorrência da difusão do cristianismo como ideologia dominante. A memória esteve presente na literatura medieval com as narrativas orais (contos populares, canções) e a escrita. Paul Zumthor (apud CARNEIRO, 2003) destaca que o uso da escritura expandiu-se com extrema lentidão nas classes dirigentes dos jovens estados europeus, pois essa prática esteve confinada, até por volta do ano 1000, a alguns mosteiros e cortes.

Na época moderna, o desenvolvimento do comércio e a intensificação das comunicações favoreceram uma maior difusão da escritura. Entretanto, o fenômeno - oralidade concomitante à escrita - ultrapassa a Idade Média e pode ser detectado ainda no século XIX e início do XX.

No século XVIII, o Iluminismo injetou uma considerável medida de racionalismo e ceticismo nos escritos da História. A consciência histórica nasceu naquele período. Os iluministas criticaram as teorias mnemônicas e a tradição escolástica e desprezaram o passado e a memória por considerá-los afetivos. Vislumbraram uma memória técnico-científica do conhecimento acumulado; o historiador buscou a ação racional.

No final do século XVIII e início do XIX, desenvolve-se o Romantismo, na Alemanha, e em outras regiões da Europa. Com o movimento romântico, nasceu a historiografia. Esta "história científica" levou à catalogação das fontes e a um ensino mais acadêmico. A tradição popular - leia-se reminiscência - passa a ser buscada por vários autores que se propõem escrever a história. Entretanto, há sempre um caráter nacionalista onde a historiografia é a história de um povo enquanto nação.

História, então, é sinônimo de memória, havendo uma relação de fusão. Elas não se distinguem. A História se apodera da memória coletiva e a transcreve em palavras. É nesse momento que a História dá voz ao "povo" pela primeira vez. O século XIX, portanto, é o momento em que a memória vai se ancorar na História.

Desde a virada do século XIX para o XX, a memória emancipou-se da História. Tornou-se matéria de literatura, em Proust; da Filosofia, em Bergson; da Psicologia (como disciplina, por intermédio de Freud); e da Sociologia, em Halbwachs. Os historiadores, desde então, têm um domínio limitado no campo da memória. Poucos estudos foram realizados sobre o tema. Na atualidade, os trabalhos dos historiadores franceses Pierre Nora e Le Goff são uns dos poucos exemplos (BURKE, 1997).

De acordo com Thompson (1992), a História Oral poderia contribuir sensivelmente para a construção da história econômica não só com a história dos grandes "nomes" da economia mundial, como também de uma pequena firma de fundição de ferro, de uma pequena cidade do interior, que não chegou a ser uma grande companhia. A documentação escrita de casos como esse é escassa; assim, somente as evidências e fontes orais têm o potencial de permitir o estudo adequado de uma atividade econômica transitória que pode ser parte essencial de um quadro mais amplo, bem como resgatar parte da história econômica de muitas regiões e localidades. 


\section{A memórla Indlvidual: lembrança e esquecimento}

A utilização do depoimento oral como fonte histórica leva a uma reflexão sobre o fenômeno da memória em si. Memória, aqui, é entendida como a propriedade de conservar certas informações, por meio de um conjunto de funções psíquicas e cerebrais. Nesse sentido, a memória - como produto de uma operação mental - é um mecanismo muito complexo, ainda hoje muito pouco conhecido, mesmo por outras ciências que a ela se dedicam, tais como a Neurologia, a Psiquiatria e a Psicologia.

A seletividade e o esquecimento estão presentes no processo da memória. Do ponto de vista psicanalítico, o esquecimento não é visto como um fenômeno passivo ou uma simples deficiência do organismo. As lembranças que "incomodam" são expulsas da consciência, mas continuam atuando sobre o comportamento no inconsciente. Portanto, selecionar ou esquecer são manipulações conscientes ou inconscientes, decorrentes de fatores diversos que afetam a memória individual.

[...] por um curtíssimo espaço de tempo temos algo que se assemelha a uma memória fotográfica, mas isso dura apenas uma questão de minutos [...] esta fase específica é muito, muito breve, e então o processo de seleção organiza a memória e estabelece espécies de vestígios duráveis, por meio de um processo químico. (THOMPSON, 1971, p. 5)

De acordo com Bergson (1999), a "memória-pura" - a verdadeira memória - mantém-se no subconsciente, ligada ao "eu profundo" e caracteriza-se pela singularidade, pois as lembranças são únicas e alcançam o indivíduo por meio de uma evocação. Somente a "memória-pura" recuperaria o passado em sua totalidade e sem nenhuma intenção utilitária. Mas, para que isto ocorra, é necessário "afastar" o cérebro, distanciá-lo da ação. Esse autor, na construção de sua teoria sobre a memória, privilegia o indivíduo e suas lembranças, ignorando o meio social do qual esse indivíduo é oriundo e que é determinante sobre ele. Portanto, ele quer mostrar que o passado se conserva inteiro e independente no espírito e que seu modo próprio de existência é inconsciente.

No estudo de Bergson, defrontam-se, por um lado, a subjetividade pura (o espírito) e, por outro, a pura exterioridade (a matéria). À primeira filia-se a memória; à segunda, a percepção. Não há, no texto de Bergson, uma tematização dos sujeitos-que-lembram, nem das relações entre os sujeitos e as coisas lembradas. Como estão ausentes os nexos interpessoais, falta, a rigor, "um tratamento da memória como fenômeno social" (BOSI, 1994, p. 54).

Halbwachs (2004), estudioso das relações entre memória e História, por sua vez, contrapõe-se a Bergson (1999). Para compreender Halbwachs, é preciso lembrar que se trata de um herdeiro e admirador da tradição da sociologia francesa. Segundo Bosi (1994), Halbwachs prolonga os estudos de Émile Durkheim que levaram à pesquisa de campo as hipóteses de Auguste Comte sobre a precedência do "fato social" e do "sistema social" sobre fenômenos de ordem psicológica, individual.

Com Durkheim, o eixo das investigações sobre a "psique" e o "espírito" desloca-se para as funções que as representações e ideias dos homens exercem no interior do seu grupo e da sociedade em geral. Essa preexistência e esse predomínio do social sobre o individual deveriam, por força, alterar substancialmente o enfoque dos fenômenos ditos psicológicos, como a percepção, a consciência e a memória (BOSI, 1994).

A obra de Halbwachs (2004), portanto, coloca a questão da memória sobre novas bases: o objeto a ser apreendido não é mais a memória, mas os "quadros sociais da memória". Nessa linha de pesquisa, as relações a serem determinadas já não ficarão ligadas ao mundo da pessoa, mas perseguirão a realidade interpessoal das instituições sociais, ou seja, a memória da pessoa está ligada à memória do grupo; e esta última à esfera maior da tradição, que é a memória coletiva da sociedade. Bosi (1994), ao analisar a obra de Halbwachs (2004), faz as seguintes considerações:

A memória do indivíduo depende do seu relacionamento com a família, com a classe social, com a escola, com a Igreja, com a profissão; enfim, com os grupos de convívio e os grupos de referência peculiares a esse indivíduo (BOSI, 1994, p. 54). 
Portanto, ao contrário de Bergson (1999), que considera que o espírito conserva em si o passado na sua inteireza e autonomia, Halbwachs (2004) dá relevo às instituições formadoras do sujeito. Ou seja, se lembramos, é porque os outros, a situação presente nos fazem lembrar. Nesse sentido, na maior parte das vezes, lembrar não é reviver, mas refazer, reconstruir, repensar, com imagens e ideias de hoje, as experiências do passado. A conservação total do passado e a sua ressurreição só seriam possíveis se o adulto mantivesse intacto o sistema de representações, hábitos e relações sociais da sua infância - o que é impossível. O passado não sobrevive "tal como foi", porque o tempo transforma percepções, idéias, juízos de realidade e de valor.

A reconstrução do passado, portanto, irá depender da integração do indivíduo em um grupo social que compartilha de suas experiências. Será esse grupo que dará sustentação a suas lembranças. Porém, segundo Halbwachs (2004), é indispensável que haja entre o grupo e o memorialista uma identidade pela qual se evidencie uma memória coletiva. Consequentemente, o isolamento, ou a falta de contato com o grupo, significará perda do passado.

Com os estudos de Halbwachs (2004), que apontam o caráter coletivo da memória, o que lhe atribui uma função social, é que se pode colocar a discussão memorialística do ponto de vista histórico-sociológico. Este redimensionamento permite reavaliar e apresentar o depoimento oral como fonte para o historiadorpesquisador.

A discussão acerca da natureza da memória leva-nos, inevitavelmente, a um dos aspectos mais polêmicos das fontes orais: a credibilidade. Para alguns historiadores tradicionais, os depoimentos orais são tidos como fontes subjetivas por nutrirem-se da memória individual, que, às vezes, pode ser falível e fantasiosa. No entanto, em História Oral, o entrevistado é considerado, ele próprio, um agente histórico. Nesse sentido, é importante resgatar sua visão acerca de sua própria experiência e dos acontecimentos sociais dos quais participou (THOMPSON, 1992; LOZANO, 2005; FRANÇOIS, 2005).

Por outro lado, a subjetividade está presente em todas as fontes históricas, sejam elas orais, escritas ou visuais. A noção de que o documento escrito possui um valor hierárquico superior a outros tipos de fonte vem sendo sistematicamente contestada em um século marcado por um avanço sem precedentes nas tecnologias de comunicação. $\mathrm{O}$ essencial consiste em aprender a detectar o que não se está dizendo e a levar em consideração o significado dos silêncios durante a entrevista. Ou seja, o que interessa em História Oral é saber por que o entrevistado foi seletivo ou omisso, pois esta seletividade tem o seu significado. Embora, em sua prática, o pesquisador depare-se com situações de trauma, comoção, fantasia, enfim, problemas humanos, ele não se utilizará de técnicas que são específicas da psicanálise para a realização de seu objetivo. O trabalho realizado pelo pesquisador que adota a História Oral visa ao registro de experiências e representações do indivíduo inserido num contexto social (THOMPSON, 1992).

No entanto, muitos entrevistados admitem que a experiência da entrevista colabora para uma autoavaliação, um questionamento e um repensar da própria vida. A maioria das pessoas, ao contar uma estória, tenta apresentar, ao mesmo tempo, um tipo de imagem consistente de si mesmo e uma imagem de autodesenvolvimento lógico.

Nos últimos dez anos, a História Oral tem-se voltado mais para o tema da subjetividade e menos para a objetividade. Portelli (1981) argumenta que as fantasias, e mesmo os casos de transferência que aparecem nas estórias, são importantes para a memória das pessoas. Deste modo, os fatos dos quais as pessoas se lembram ou se esquecem seriam a substância da qual é feita a história. Esses fatos apenas sobrevivem se fazem sentido para as pessoas e, por sobreviverem, tornam-se fatos históricos. Consequentemente, não há fonte oral falsa. Portelli (1981) salienta, ainda, que a diferença da fonte oral encontra-se no fato de que os depoimentos não verdadeiros são psicologicamente verdadeiros, e que esses "erros", às vezes, revelam mais dados que o relato exato. A credibilidade da fonte oral, portanto, não deve ser avaliada por aquilo que o testemunho oral pode frequentemente esconder, por sua inexatidão para com os fatos, mas pela divergência deles, onde imaginação e simbolismo estão presentes.

De acordo com Pinon, a memória é 


\section{[...] como uma entidade que persegue o ser humano e que não está a serviço do homem tanto como ele} pensa. Ao mesmo tempo, a memória é a matéria mais irrenunciável do homem. A memória não tem coesão, não tem lógica, não tem simetria e é fragmentada, múltipla, confusa, um turbilhão que se apossa do seu ser, da sua integridade. $(1999$, p. 5)

Assim, segundo a escritora, somos todos narradores; ainda que não escrevamos, nossa memória está sempre narrando os fatos que vivemos, ou que pensamos ter vivido.

Ainda sobre as fantasias das pessoas, Thompson (1992) argumenta que inventar um passado imaginário, que deve ter acontecido, é uma forma de preservar suas crenças e sua ideologia. Além disso, segundo o autor, a subjetividade é, de fato, a única força da história oral, pois aquilo em que o depoente acredita é, para ele, mais importante do que aquilo que realmente acontece.

Sabe-se que as memórias são fragmentadas e que os indivíduos as reconstroem enquanto falam. A entrevista ajuda as pessoas a recuperar seus traumas e as leva a uma melhor compreensão de si e de seu passado. Portanto, respeitar e valorizar as diferenças individuais numa sociedade cada vez mais massificada é fundamental. É aí que se destaca a dimensão social da História Oral e a atuação do pesquisador (THOMPSON, 1992; PORTELLI, 1998; FRANÇOIS, 2005).

Quanto à fidelidade, o pesquisador deve ser fiel à entrevista, porque a fita gravada é um documento histórico que pode ser usado por outros pesquisadores. Nunca houve, na história da humanidade, a possibilidade da não manipulação dos diálogos. A fonte oral - que é fonte porque está gravada numa fita não necessariamente transcrita - introduz uma revolução historiográfica porque impede que os diálogos sejam manipulados, como ocorria, em muitos casos, no passado e ainda ocorre no presente. Entretanto, deve-se considerar que "la grabación solo es un médio y la cinta magnética es un estado provisional de la constitución del documento" (JOUTARD, 1986 apud ALCANTUD, 1992, p. 3). Assim, deve-se dar maior importância ao texto final. Meihy (2002) assume um posicionamento mais radical em relação à transcrição da entrevista. Para esse autor, não são as palavras do depoente, mas, sim, o texto final que tem teor literário e expressa as ideias e a essência do que foi dito.

Por conseguinte, neste trabalho, entende-se que a História Oral pressupõe projeto, pesquisa, técnica de entrevista, posicionamento ético e respeito com relação ao entrevistado. Aliás, saber ouvir é a característica fundamental do entrevistador. Este não é passivo nem neutro, na medida em que, com suas perguntas, participa e dirige o processo da entrevista, prepara o roteiro, seleciona as perguntas e introduz questões e temas a serem abordados pelo entrevistado. $\mathrm{O}$ documento final é o resultado de um diálogo entre pesquisador e pesquisado. Além disso, reside na História Oral a grande possibilidade da integração de fontes, ou seja, a confrontação entre as fontes escritas e orais e a sua utilização multidisciplinar.

\section{A Histórla na análise organizacional}

Até que ponto os estudos historiográficos e de memória podem contribuir na análise de organizações? A análise organizacional chegou ao Brasil, segundo Bertero e Keinert (1994), juntamente com a Administração enquanto atividade profissional e preocupação acadêmica, sobretudo com a implantação dos primeiros cursos voltados para a área pública e empresarial nas décadas de 1950 e 1960, embora a Administração tenha se originado em outras sociedades e culturas como campo de conhecimento e de reflexão. Naturalmente, a análise organizacional em nosso país acaba por carregar as marcas do management norte-americano, pois boa parte dos professores foi "formada" por escolas da América do Norte. O que explica, inclusive, por que o modelo dos currículos dos cursos de Administração é fortemente delineado pela proposta norte-americana. Mais recentemente, algumas escolas têm apresentado uma posição crítica diferente, mas todos ainda são influenciados pela visão de management. Embora necessário, o debate epistemológico da Administração não alcançou a dimensão que a disciplina requer.

Essa forte herança norte-americana influencia-nos na adoção de comportamentos, em decisões e implantação de medidas, inclusive na construção de modelos teóricos e aplicativos nada originais, que nem sempre se 
aplicam à nossa realidade ou estão afinados com a sociedade brasileira (BERTERO; KEINERT, 1994; VERGARA; HEMAIS, 2000; HEMAIS; VERGARA, 2001). As experiências estrangeiras são demasiadamente valorizadas no Brasil em detrimento de casos nacionais. Bertero e Keinert (1994) ressaltam que as publicações que envolvem análise organizacional quase não adotam o paradigma interpretativo e marxista até as décadas de 1970 e 1980, o que denuncia um predomínio do paradigma funcionalista na análise organizacional até hoje (MORGAN, 1990 apud BURRELL; MORGAN, 1979).

Entretanto, no campo da Administração, vem-se assistindo, ao longo das últimas décadas, a um movimento que evidencia o vigor de uma área do conhecimento que busca sua afirmação enquanto campo científico estabelecido (SCANDURA; WILLIANS, 2000). Mesmo que isso explicite carências metodológicas, conceituais - e, por que não dizer, interdisciplinares - que esta área carrega, é impossível não reconhecer os avanços alcançados. Estes têm recuperado em grande medida a contribuição histórica das experiências empresariais e de gestores.

Os relatos e experiências empresariais têm se tornado um importante tópico para o entendimento das organizações. Surgem como a possibilidade concreta de reconhecer o papel da História como elemento vital para construir o futuro. A literatura basicamente traz a história de grandes casos internacionais. Poucas são as obras que retratam casos nacionais. Tentativas mais recentes e bem-sucedidas de difundir casos brasileiros foram as experiências do professor Jacques Marcovitch, da Universidade de São Paulo, com a coletânea Pioneiros \& empreendedores: a saga do desenvolvimento no Brasil, e das ex-professoras e pesquisadoras Ligia Maria Leite Pereira e Maria Auxiliadora de Faria, da Universidade Federal de Minas Gerais, com os livros Amaro Lanari Júnior: pensamento e ação de um siderurgista e Nansen - 70 anos de precisão: memória histórica. Cléber Aquino, a partir de meados da década de 1980, por meio do seu estruturado Programa de História Empresarial Vivida, desenvolveu uma produção sistemática, com objetivos acadêmicos, que também merece destaque.

Cabe mencionar também o trabalho de Agrícola Bethlem, no final da década de 1980, versando sobre gerência à brasileira, e o de Marcos Cobra, no início da década de 1990, expondo casos brasileiros de sucesso, na área de marketing. Apesar da falta de fôlego, merece menção, da mesma forma, a contribuição de Ricardo Semler com seu best seller Virando a própria mesa. O jovem empresário "abriu as veias" da cultura empresarial brasileira, e na oportunidade revelou um retrato relativamente fiel do universo das empresas nacionais. Como iniciativa isolada, não se deve omitir ainda a produção do grupo empresarial Odebrecht, que promove e divulga uma interessante discussão sobre a aplicação da filosofia do seu fundador nas empresas do grupo. Uma visão panorâmica do pensamento e da obra de alguns líderes empresariais nacionais está, também, presente na bem acabada coleção, do ponto de vista gráfico, Pense grande, de quatro volumes, sob o patrocínio do extinto Banco Multiplic. Finalmente, uma importante contribuição voltada a essa dissecação da história de empresas nacionais é o livro $O$ estilo brasileiro de administrar, de Betânia Tanure de Barros e Marco Aurélio Spyer Prates.

No campo dos negócios, a saga do desenvolvimento tem sido igualmente negligenciada em nome das flutuações dos ciclos econômicos - o que é um grande erro de avaliação. Exatamente para evitar perdas e compreender as razões de seus êxitos é que se deve reler a história dos negócios. Nenhuma geração completa sua obra e todos os bons empreendimentos exigem continuidade. Os fatos se repetem com grande teimosia em qualquer plano de atividade, especialmente na administração. Empreender não consiste apenas em termos idéias próprias, mas em sabermos como outros, antes de nós, conduziram à prática os seus projetos de vida. (MARCOVITCH, 2005, p. 8)

Mendonça (2000) confessa certo desconforto quanto ao uso intenso e maciço de literatura estrangeira cheia de casos desenvolvidos em contextos de ambiente empresarial bastante diferente ao do brasileiro. Apesar da tendência inescapável da globalização, o autor recupera a ideia de que muito do que vale para interpretar o sucesso "lá" não se aplica de forma automática "aqui". A história empresarial brasileira dispõe de casos de sucesso que não deixam a desejar a nenhum case de outro país e, o que é mais importante, tais casos indicam que empresas souberam e sabem vencer com traços culturais autóctones. O que se precisa fazer é estudá-los com o olhar científico, técnico, administrativo, gerencial e empresarial adequados e atuais, extraindo daí, 
inclusive, lições para outras empresas, fontes para pesquisas acadêmicas, informações e saber para a sociedade brasileira de hoje e do futuro (DAVEL; ALCADIPANI, 2003). Entretanto, os poucos casos nacionais relatados referem-se a grandes empreendimentos. O corriqueiro, o cotidiano da administração de empresas ainda é negligenciado.

A Administração tem-se mostrado uma ciência aberta a inovações, sejam elas endógenas ou exógenas à área. Todavia, em se tratando de metodologia, em especial na forma de apresentação dos relatórios de pesquisa, parece haver tendência a certo conservadorismo. De acordo com Cavedon (2001), as pesquisas sobre cultura organizacional, por exemplo, já incorporaram o aporte teórico e metodológico da Antropologia, porém, apesar de fazer uso do método etnográfico, o pesquisador na área de Administração resiste ao uso da primeira pessoa do singular, uma postura que é muito cara ao antropólogo/etnógrafo que costuma dizer que foi ao campo, que "lá esteve". Os administradores, formados numa academia que privilegia o uso do impessoal, relutam em desconstruir-se no sentido de se colocar no texto, assumindo uma postura do ético (categoria do pesquisador) sem confundir-se com o êmico (categoria dos informantes). Esse apego ao distanciamento sob a forma verbal revela certa tendência estética mais ortodoxa e, talvez, por isso, o administrador/pesquisador ainda não tenha se aventurado pelos caminhos, por exemplo, da fotoetnografia. ${ }^{4}$

Há que se registrar, contudo, que os vídeos vêm sendo amplamente utilizados como um recurso didático; já as fotos, no máximo, como ilustrações das narrativas apresentadas sob a forma de dissertações, teses, relatórios de pesquisas (CAVEDON, 2001). Os estudiosos mais ortodoxos dizem que, ao optar por essas diferentes linguagens, corre-se o risco de descaracterizar a construção da ciência administrativa. Acredita-se que tal assertiva seja passível de contestação na medida em que o mundo avança tanto em conteúdo como em forma e que não se pode mais prescindir de todas as variantes existentes quando elas forem cabíveis, ainda mais em tempos de complexidade. Assim, de uma arena quase que consensualmente dominada por concepções funcionalistas, que privilegiam tradições ortodoxas quantitativas de pesquisa, os estudos organizacionais passaram a compor um rico caleidoscópio. Fragmentação, diversidade e pluralismo representam o panorama atual.

Segundo Cabral (1998), nos últimos anos, no Brasil e no exterior, tem-se observado uma aproximação crescente entre a Administração e a Antropologia, que intensifica as ações nessa fronteira interdisciplinar, sugere a emergência de um campo híbrido - a chamada antropologia das organizações - e, acima de tudo, descortina novos setores e formas de atuação profissional no ambiente organizacional. No que se refere à Administração, poder-se-ia até temer que esse movimento se constituísse em mais uma moda, expediente tão característico nessa área. Contudo, as evidências revelam que se está diante de um fenômeno próprio da tendência contemporânea, que conduz a ciência ao fortalecimento da construção de saberes interdisciplinares e os cientistas a tornarem-se mais abertos ao diálogo e ao trabalho conjunto com colegas de outras disciplinas.

Ao se abordar a interdisciplinaridade entre as várias áreas de conhecimento e a Administração, deve-se trazer o debate sobre a questão metodológica no estudo da Administração que, inclusive, vem crescendo nos últimos anos. Este debate parece estar relativamente concentrado em torno de questões sobre os paradigmas, sobre as abordagens subjetivistas ou objetivistas e sobre os métodos quantitativos e qualitativos. Pode-se perceber que, apesar de alguns acreditarem que certas questões já estejam resolvidas, este é um tema que ainda vai proporcionar grandes discussões teóricas. Um tópico que ainda merece atenção e um maior aprofundamento é a pesquisa qualitativa e os tipos de investigação nela empregados.

Na área da Administração, a pesquisa qualitativa, apesar de ter sido utilizada com regularidade por antropólogos e sociólogos, só começou a ganhar espaço a partir da década de 1970 (GODOY, 1995). Para Rocha e Ceretta (1998), os estudos que empregam uma metodologia qualitativa podem descrever a complexidade de determinado problema, analisar a interação de certas variáveis, compreender e classificar processos dinâmicos vividos por grupos sociais, contribuir no processo de mudança de determinado grupo e

4 O significado de "fotoetnografia" está diretamente vinculado ao de Etnografia, ciência que estuda os grupos da sociedade, suas características antropológicas, sociais e culturais. Quando a fotografia é utilizada como recurso principal na realização de uma pesquisa etnográfica, esta se torna uma fotoetnografia. A fotografia etnográfica recupera informações relacionadas aos diferentes tipos de etnias. Além disso, reúne dados do conhecimento que podem servir, portanto, como fonte de comparação histórica, visto que a cultura e os costumes das etnias estão sujeitos a mudanças. 
possibilitar, em maior nível de profundidade, o entendimento das particularidades do comportamento dos indivíduos.

Nas pesquisas de cunho qualitativo, tanto a delimitação quanto a formulação do problema possuem características próprias. Ambas exigem do pesquisador a imersão no contexto que será analisado. A análise do passado e do presente é crucial para que haja uma maior isenção do investigador com relação ao fenômeno social que pretende desvendar. Para tanto, a delimitação é feita em campo onde a questão inicial é explicitada, revista e reorientada com base no contexto e nas informações das pessoas ou grupos envolvidos na pesquisa. Entretanto, pode-se perceber que algumas perspectivas teóricas originadas na Sociologia e na psicologia social ainda não são satisfatoriamente exploradas na pesquisa em Administração.

Vários estudos têm evidenciado os perfis metodológicos predominantes nas diversas pesquisas desenvolvidas na área de Administração. Alguns autores afirmam que há uma predominância de trabalhos com um caráter mais quantitativo (MARTINS, 1994; NEVES, 1996; SILVA, 2004), enquanto outros apontam a predominância dos métodos qualitativos (BUFONI, 2002; CALDAS, TONELLI; LACOMBE, 2002). No entanto, há indícios de que existe uma forte influência anglo-saxônica nos estudos administrativos brasileiros (VERGARA; CARVALHO JR., 1995; RODRIGUES; CARRIERI, 2001).

De forma geral, os focos reflexivos sobre a produção científica em Administração sugerem que, apesar do aumento do número de publicações, o campo ainda carece de um delineamento epistemológico mais claro. Apesar do consenso por um percurso metodológico mais robusto, observa-se a existência de pontos de vista antagônicos quanto às abordagens de análise predominantes no campo da Administração, o que se evidencia, inclusive, na recorrente divisão dos metaestudos por áreas temáticas da Administração. Segundo Burrell (1999), a construção do conhecimento em Administração é um campo rico para debates ontológicos e epistemológicos.

Monteiro, Veiga e Doornik (2005) levantam os seguintes questionamentos: estariam os modelos matemáticos sendo empregados para justificar uma "cientificidade superior" nas pesquisas; seriam os métodos quantitativos adequados para a compreensão plena dos fenômenos sociais propostos? Estas questões permanecem em aberto para a produção científica nacional. Assim, o uso de "multimétodos", enquanto ferramenta para equilibrar as vantagens e desvantagens de abordagens de pesquisa divergentes (JICK, 1979 apud MONTEIRO, VEIGA; DOORNIK, 2005), pode ser uma prática cada vez mais remota no âmbito da Administração.

Em decorrência da evolução e das revoluções ocorridas e ainda em andamento, os estudos organizacionais têm oscilado da ciência normal para a contraciência; do mainstream para o desconstrucionismo, da modernidade para a pós-modernidade. Como Clegg e Hardy (1996) afirmam, à medida que novas perspectivas têm proliferado, maiores oportunidades de iniciar novas conversações têm-se manifestado: mais diversidade, mais discordância. Mas, também, mais pontos de interseção e mais motivos para o diálogo, debate e disputa.

Logo, abordar a pesquisa qualitativa como um método de estudo utilizado nas Ciências Sociais é sempre um desafio. De acordo com Rocha e Ceretta (1998), as fronteiras que separam os tipos de estudos quantitativos dos qualitativos não são claras. O que se pode afirmar é que, em algum momento na tarefa investigatória, eles se complementam. No entanto, é relevante que o estudioso que mergulha num estudo com características qualitativas tenha um cuidado maior que aquele que se lança na mensuração quantitativa. É imprescindível, neste caso, que o pesquisador busque se separar dos pré-julgamentos inerentes ao ser humano. Isto porque ele estará em contato direto com os investigados, podendo inclusive ser manipulado ou influenciado a pensar e concluir como estes querem. Não se deve esquecer, portanto, que tanto pesquisador quanto pesquisado ou pesquisados estão representando papéis naquele momento. Além disso, é vital para o sucesso do trabalho qualitativo que o investigador domine a corrente epistemológica que selecionou para o seu estudo.

Assim, o advento de estudiosos sociais desprovidos de uma visão cartesiana e linear e interessados em desenvolver estudos que lhes dessem condições reais de aprofundar seus trabalhos fez crescer o interesse pelos estudos de cunho qualitativo. A luta dos adeptos da pesquisa qualitativa recai diretamente na não aceitação do determinismo mecanicista de Laplace e mecanicista da física newtoniana, herdada do positivismo. Com isso os estudos historiográficos surgem como uma nova oportunidade de pesquisa não só na área de Ciências Sociais, 
mas, sobretudo, no campo da Administração, com foco na análise organizacional. A História Oral também se apresenta como um recurso que pode ser adotado em estudos organizacionais. De acordo com Fábio Vizeu (2007), alguns temas são fundamentais, sob a pesquisa histórica, para os estudos organizacionais brasileiros: a estruturação do pensamento administrativo brasileiro; as ideologias e discursos associados a práticas organizacionais; os estudos organizacionais fundamentados na historiografia social brasileira e a história corporativa e de negócios no Brasil.

O pesquisador, no entanto, deve estar ciente das dificuldades que enfrentará nos estudos qualitativos em decorrência do tempo necessário à execução dos trabalhos, bem como da disponibilidade e boa vontade dos pesquisados, principalmente quando a opção metodológica for pela História Oral. Para finalizar a discussão é relevante mencionar que, mesmo com certas dificuldades, acredita-se que os estudos qualitativos e especificamente aqueles voltados para os métodos historiográficos são molas propulsoras para o profundo conhecimento das organizações.

Em nossa experiência na Universidade Estadual do Sudoeste da Bahia, UESB, a utilização da pesquisa em História e memória vem conquistando importantes espaços, tanto no ensino como na pesquisa. Além disso, o diálogo entre a História e a Administração tem sido promissor, uma vez que o resultado dessa aproximação dos campos poderá servir para aprofundar o conhecimento organizacional.

A análise histórica foi instituída como atividade de ensino, no curso de graduação em Administração, com sua reforma curricular em 1995. Na ocasião, foi criada uma disciplina obrigatória intitulada "Administração Brasileira", que começara de fato no final dos anos 90, com um programa voltado para a pesquisa, catalogação e estudo da história de vida dos empresários da região sudoeste da Bahia. Nessa matéria os alunos percebiam os desafios e perspectivas da construção dos empreendimentos, tanto nos seus aspectos positivos quanto em suas dificuldades. Num contexto formado, sobretudo, por pequenas e médias empresas familiares, é interessante perceber a relação entre a trajetória da família e da organização. A disciplina também se ocupava da análise de trajetórias de gestores públicos de destaque na região. A coordenação do curso percebeu, de imediato, que essa experiência provocava grande impacto na aprendizagem dos alunos e na sua percepção na relação administrador, cidadão, família e sociedade. A História e a memória logo se mostraram um excelente método de ensino.

O resultado deste processo foi tal que repercutiu na incipiente estrutura de pesquisa da área de Administração na instituição. Primeiro, pela criação de um grupo de pesquisa em empreendedorismo, que tem como uma das linhas principais a análise da história de vida e memória dos empresários do sudoeste da Bahia. Esse grupo tem hoje um amplo acervo em vídeos com depoimentos da maioria dos empreendedores regionais. A partir daí vários estudantes foram instigados a realizar seus projetos monográficos sobre a história de vida dos empreendedores, a trajetória de suas famílias e organizações. Atualmente, a instituição possui um grande acervo que revela a construção dos negócios locais, os discursos dos empresários e a memória sobre o perfil da região.

Em outro campo, também na Universidade Estadual do Sudoeste da Bahia, a pesquisa histórica tem se apresentado como um importante instrumento de gestão e recurso para a análise organizacional. Nesse caso, trata-se da gestão da própria universidade, na reformulação de sua estratégia. Com a publicação do livro UESB: memória, trajetórias e vivências (VILAS BÔAS, 2001), que contém depoimentos de experiências individuais e coletivas de professores, técnicos administrativos e ex-alunos, foi construído um instrumento que não só preserva a memória coletiva dos sujeitos sociais da instituição, mas, sobretudo, apresenta-se como referência à percepção de como se deu a construção da identidade institucional e de como os desafios devem ser superados. Esse material, além de contribuir para a consolidação da memória da instituição, serviu como um dos guias para a análise do ambiente interno da organização, na identificação de competências, forças e fraquezas. Tal documento proporcionou também que a instituição obtivesse uma visão mais clara da sua trajetória e dos novos caminhos que deveriam ser traçados.

O uso da memória, por meio de olhares privilegiados dos que construíram a UESB, ajudou a instituição a conhecer e desenvolver suas competências: da estratégia institucional aos desdobramentos departamentais. Tal metodologia revelou-se uma nova forma de captar informações e analisar o ambiente. Isso foi particularmente 
importante no curso de Administração, no qual as análises contribuíram não só na formulação da estratégia como também na nova reformulação do curso, com novas diretrizes curriculares.

Certamente este não foi o único instrumento de análise utilizado. Aliás, foi um suporte a mais para a percepção dos fatos que nos cercam. Ou seja, a história de vida e a memória tornam-se novos olhares diante da complexidade organizacional. Porém, tanto na pesquisa quanto na gestão, o uso da triangulação é cada vez mais recomendado para fortalecer a consistência das informações. Pensamos aqui na perspectiva de Morgan (1996) quando defende que a análise organizacional deve ser feita por meio de múltiplos olhares, ou seja, o maior número de instrumentos de análise permite um melhor diagnóstico e uma intervenção mais efetiva.

Assim como Vizeu (2007), acredita-se que a pesquisa histórica deve ser empreendida com o objetivo de tornar mais inteligível a realidade organizacional brasileira contemporânea. A nosso ver, o diálogo entre a História e a Administração pode permitir, inclusive, uma observação mais acurada das peculiaridades das organizações. Ou seja, a abordagem histórica pode ser uma via para que os "estudos organizacionais brasileiros vislumbrem sua identidade acadêmica, já que, [...] a forte influência da literatura estrangeira reflete a falta de originalidade por parte do pesquisador nacional” (VIZEU, 2007, p. 14).

\section{Considerações finals}

A discussão apresentada neste artigo tem como objetivo sensibilizar os pesquisadores da área de Administração a respeito da potencialidade da historiografia e da memória como ferramentas para a análise organizacional. Sob essa diretriz, a História Oral apresenta-se com um grande potencial, pois proporciona uma visão multidisciplinar da realidade organizacional.

Tendo por parâmetro o grande número de pesquisas e levantamentos que vêm sendo feitos na pesquisa em Administração, com utilização da técnica da entrevista gravada, é possível inferir que parte dessas entrevistas seja de História Oral. No entanto, são feitas sem que se lhes atribua essa denominação e, possivelmente, sem seguir os preceitos que regem sua execução, o que as tornaria mais robustas do ponto de vista metodológico.

Quando vamos a campo realizar entrevistas em profundidade e levantamos, de nossos entrevistados, como fonte de dados, aspectos de suas experiências, visões, interpretações, memórias, opiniões, seu entendimento sobre um assunto, seus pensamentos, ideias, emoções, sentimentos, percepções, comportamento, práticas, ações, atividades, interações, crenças, compromissos, produtos, relacionamentos etc., com certeza estamos trabalhando com fenômenos que têm muito a revelar sobre a realidade social e que se coadunam perfeitamente com a História Oral.

Também é possível afirmar que a pesquisa qualitativa em Administração poderia ser mais enriquecida ainda com a adoção da História Oral. O argumento é de que, se a pesquisa em Administração pode valer-se da abordagem historiográfica como método, seria ainda mais enriquecida com a utilização da metodologia da História Oral. Isto porque esta refere-se a uma história do presente e tem como pressuposto o passado como continuidade de hoje, ou seja, o passado está na vida presente das pessoas. Como grande parte da vida das pessoas decorre no interior das organizações, é na maneira como se institui o passado que se criam as condições imaginárias para definição dos projetos das pessoas dentro das organizações.

Um dado importante é que a História Oral possibilita captar as experiências elaboradas por indivíduos pertencentes a categorias sociais cujas percepções e intervenções geralmente são excluídas da história e documentação oficiais das organizações. Assim, é possível registrar sua visão de mundo, suas aspirações e utopias e, consequentemente, aquelas do grupo social ao qual pertencem. A História Oral tem condições de recuperar a visão das pessoas comuns dentro das empresas - os trabalhadores e operários - trazendo à tona as "memórias subterrâneas" de grupos excluídos do processo decisório, que, de outra forma, não seriam consideradas nem fariam parte da História.

Vista inicialmente como uma contra-história, uma história contra a tradição positivista, a História Oral tinha como ideal reconciliar o saber com o povo, assumir um projeto de democratização da História, propondo-se a devolver a palavra ao povo, ao rural, ao primitivo. Assim, o uso da História Oral como instrumento 
metodológico em estudos organizacionais pode enriquecer as (re)interpretações sobre as realidades das organizações.

Convém observar, ainda, que a discussão aqui levantada carece, certamente, de um amadurecimento teórico e do acúmulo de conhecimentos a respeito de outros estudos que possam, por sua vez, enriquecer o trabalho. É, portanto, pelo fato de estar limitado por essa condição de imaturidade que o presente estudo apresenta-se com a pretensão de oferecer uma contribuição para uma reflexão a respeito da inserção da História Oral como recurso metodológico em estudos organizacionais. 


\section{Referênclas}

ALCANTUD, J. A. G. Historia y antropología: de la teoría a la metódica pasando por las fuentes. Gazeta de Antropología, Coimbra, $n$. 9, 1992. Disponível em: <http://www. ugr.es/ pwlac/Gog_06JoseAntonio_Gonzalez_Alcantud.html>. Acesso em: 15 mai. 2006.

AMADO, J.; FERREIRA, M. de M. (Coord.). Usos \& abusos da história oral. Rio de Janeiro: FGV, 2005.

BARBOZA, J. J. História oral e hermenêutica. Primeira Versão, Porto Velho, ano I, n. 105, ago. 2002.

BENJAMIN, Walter. O narrador: considerações sobre a obra de Nikolai Leskov. In: Magia e técnica, arte e política. São Paulo: Brasiliense, 1985. v. 1. (Coleção Obras Escolhidas).

BERGSON, H. Matéria e memória. São Paulo: Martins Fontes, 1999

BERTERO, C. O.; KEINERT, T. M. M. A evolução da análise organizacional no Brasil (1961-93). RAE, São Paulo, v. 34, n. 3, p. 81-90, mai./jun. 1994 .

BOSI, E. Memória e sociedade: lembrança de velhos. São Paulo: Companhia das Letras, 1994.

BUFONI, André Luiz. O rigor na exposição dos estudos de caso simples: um teste empírico em uma universidade brasileira. In: ENCONTRO NACIONAL DA ASSOCIAÇÃO DOS PROGRAMAS DE PÓS-GRADUAÇÃO EM ADMINISTRAÇÃO, 26, 2002, Salvador. Anais... Salvador: ANPAD, 2002.1 CD.

BURKE, P. A escola dos Annales (1929-1989): a Revolução Francesa da historiografia. São Paulo: Fundação Editora UNESP, 1997.

BURRELL, G. Ciência normal, paradigmas, metáforas, discursos e genealogia da análise. In: CLEGG, S.(Org.) Handbook de estudos organizacionais. São Paulo Atlas, 1999.

CABRAL, Augusto Cézar de Aquino. Reflexões sobre a pesquisa nos estudos organizacionais: em busca da superação da supremacia dos enfoques positivistas. In: ENCONTRO NACIONAL DA ASSOCIAÇÃO DOS PROGRAMAS DE PÓS-GRADUAÇÃO EM ADMINISTRAÇÃO, 22, 1998, Foz do Iguaçu. Anais... Foz do Iguaçu: ANPAD, 1998. 1 CD.

CALDAS, A. L. O historicismo e a Escola dos Annales. Primeira Versão, Porto Velho, ano I, n. 183, jan. 2004.

CALDAS, M. P.; TONELLI, M. J.; LACOMBE, B. M. G. Espelho, Espelho Meu: Metaestudo da Produção Científica em Recursos Humanos nos ENANPADs na década de 9o. In: ENCONTRO NACIONAL DA ASSOCIAÇÃO DOS PROGRAMAS DE PÓSGRADUAÇÃO EM ADMINISTRAÇÃO, 26, 2002, Salvador. Anais... Salvador: ANPAD, 2002. 1 CD.

CALVINO, I. A palavra escrita e não-escrita. In: AMADO, J.; FERREIRA, M. de M. (Coord.). Usos \& abusos da história oral. Rio de Janeiro: FGV, 2005

CARNEIRO, C. F. Paul Zumthor e as marcas da oralidade. Primeira Versão, Porto Velho, ano I, n. 134, fev. 2003.

CAVEDON, Neusa Rolita. Recursos Metodológicos e Formas Alternativas no Desenvolvimento e na Apresentação de Pesquisas em Administração. In: ENCONTRO NACIONAL DA ASSOCIAÇÃO DOS PROGRAMAS DE PÓS-GRADUAÇÃO EM ADMINISTRAÇÃO, 25, 2001, Campinas. Anais... Campinas: ANPAD, 2001. 1 CD.

CLEGG, S.; HARDY, C. Introduction: organizations, organization and organizing. In: CLEGG, S.; HARDY; C.; NORD, W. (Eds.). Handbook of Organization Studies. London: Sage, 1996.

DAVEL, E.; ALCADIPANI, R. Estudos críticos em administração: a produção científica brasileira nos anos 1990. RAE, v. 43, n. 4, 2003.

FRANÇOIS, E. A fecundidade da história oral. In: AMADO, J.; FERREIRA, M. de M. (Coord.). Usos \& abusos da história oral. Rio de Janeiro: FGV, 2005

GODOY, A. S. Introdução à pesquisa qualitativa e suas possibilidades. RAE. São Paulo, v. 35, n. 2, p. 57-63, mar./abr. 1995. HALBWACHS, M. A memória coletiva. São Paulo: Centauro, 2004

HEMAIS, Bárbara; VERGARA, Sylvia Constant. O jeito brasileiro de publicar em estudos organizacionais. O\&S, v. 8, n. 20, jan./abr. 2001. 
ICHIKAWA, E. Y.; SANTOS, L. W. dos. Vozes da História: Contribuições da História Oral à Pesquisa Organizacional. In: ENCONTRO NACIONAL DA ASSOCIAÇÃO DOS PROGRAMAS DE PÓS-GRADUAÇÃO EM ADMINISTRAÇÃO, 27, 2003, Atibaia. Anais... Atibaia: ANPAD, 2003. 1 CD.

JOUTARD, P. História oral: balanço da metodologia e da produção nos últimos 25 anos. In: AMADO, J.; FERREIRA, M. de M. (Coord.). Usos \& abusos da história oral. Rio de Janeiro: FGV, 2005.

LOZANO, J. E. A. Prática e estilos de pesquisa na história oral contemporânea. In: AMADO, J.; FERREIRA, M. de M. (Coord.). Usos \& abusos da história oral. Rio de Janeiro: FGV, 2005

MARCOVITCH, J. Pioneiros \& Empreendedores: a saga do desenvolvimento no Brasil. São Paulo: Edusp/Saraiva, 2005.

MARTINS, G. A. Metodologias convencionais e não convencionais e a pesquisa em administração. Caderno de Pesquisas em Administração, São Paulo, v. 00, n. 0, 2. Sem., 1994.

MEIHY, J. C. S. B. Manual de história oral. São Paulo: Edições Loyola, 2002.

MENDONÇA, Luis Eduardo Carvalheira de. História de empresas brasileiras: tem espaço na academia? Questionamentos exploratórios e conclusões preliminares. In: ENCONTRO NACIONAL DA ASSOCIAÇÃO DOS PROGRAMAS DE PÓS-GRADUAÇÃO EM ADMINISTRAÇÃO, 24, 2000, Rio de Janeiro. Anais... Rio de Janeiro: ANPAD, 2000. 1 CD.

MONTEIRO, Plínio Rafael Reis; VEIGA, Ricardo Teixeira; DOORNIK, Bernardus Ferdinandus Nazar Van. Abordagens epistemológicas em administração: isolamento, hegemonia ortodoxa ou concepção pluralista?. In: ENCONTRO NACIONAL DA ASSOCIAÇÃO DOS PROGRAMAS DE PÓS-GRADUAÇÃO EM ADMINISTRAÇÃO, 29, 2005, Brasilia. Anais... Brasília: ANPAD, 2005. 1 CD.

MORGAN, Gareth. Imagens da Organização. São Paulo: Atlas, 1996.

Paradigm diversity in organizational research. In: HASSARD, J.; PYM, D. (Eds.). The theory and philosophy of organizations: critical issues and new perspectives. London: Routlegde, 1990. Chapter 1, p. 13-29.

NEVES, José Luis. Pesquisa qualitativa - Características, usos e possibilidades. Caderno de Pesquisas em Administração, São Paulo, V. 1, n. 2, 2. Sem., 1996.

PINON, N. A paixão da memória. Folha de São Paulo, São Paulo, Caderno Mais!, p. 5, 5 ago. 1999.

PORTELLI, A. The peculiarities of oral history. History Workshop Journal, n, 12, p. 96-107, 1981.

Ciência do indivíduo. Folha de São Paulo, São Paulo, 07 jun. 1998. Caderno Mais!. Disponível em: <http://www1.folha.uol.com.br/fsp/mais/fs07069823.htm>. Acesso em: og jul. 2006.

ROCHA, Rudimar Antunes da; CERETTA, Paulo Sérgio. Pesquisa qualitativa: um desafio à ciência social. In: ENCONTRO NACIONAL DA ASSOCIAÇÃO DOS PROGRAMAS DE PÓS-GRADUAÇÃO EM ADMINISTRAÇÃO, 22, 1998, Foz do Iguaçu. Anais... Foz do IguaçU: ANPAD, 1998. 1 CD.

RODRIGUES, S. B.; CARRIERI, A. P. A tradição anglo-saxônica em Estudos Organizacionais brasileiros. RAC, Edição Especial, p. 81102, 2001.

SALAMA, A. The use of an organisation's biography as a research method. Management Education and Development, v. 23, n. 3, p. 225-233, Autumn, 1992.

SARDE NETO, E. História oral: uma síntese reflexiva. Primeira Versão, Porto Velho, ano I, n. 159, jun. 2003.

SCANDURA, T. A.; WILLIAMS, E. A. Research methodology in management: Current practices, trends, and implications for future research. Academy of Management Journal, v. 43, n. 6, p. 1248-1264, Dec. 2000.

SILVA, J. F. Métodos quantitativos na pesquisa em administração: usos e abusos. Anpad: opinião, 20 mar. 2004. Disponível em: <http://www.anpad.org.br/opiniao_jorge_site_main.html>. Acesso em: ogjul. 2006.

SMOLKA, A. L. Bustamante. A memória em questão: uma perspectiva histórico-cultural. Educação \& Sociedade, v. 21, n. 71, Campinas, jul. 2000. 
THOMPSON, P. Problems of Method in Oral History PAUL. Oral History Journal, v. 1, n. 4, 1971

A voz do passado: história oral. Rio de Janeiro: Paz e Terra, 1992

VERGARA, S.; CARVALHO JR, D. S. Nacionalidade dos autores referenciados na literatura brasileira sobre organizações. In: ENCONTRO NACIONAL DA ASSOCIAÇÃO DOS PROGRAMAS DE PÓS-GRADUAÇÃO EM ADMINISTRAÇÃO, 19, 1995, João PesSOa. Anais... João Pessoa: ANPAD, 1995. 1 CD.

VERGARA, Sylvia Constant; HEMAIS, Bárbara. A cultura anglo-americana na produção brasileira: um estudo de intertextualidade de trabalhos em estudos organizacionais. In: ENCONTRO NACIONAL DA ASSOCIAÇÃO DOS PROGRAMAS DE PÓS-GRADUAÇÃO EM ADMINISTRAÇÃO, 24, 2000, Rio de Janeiro. Anais... Rio de Janeiro: ANPAD, 2000. 1 CD.

VILAS BÔAS, Elzir da Costa. (Org.). UESB: memória, trajetórias e vivências. Vitória da Conquista: Edições UESB, 2001.

VIZEU, Fabio. Em algum lugar do passado: contribuições da pesquisa histórica para os estudos organizacionais brasileiros. In: ENCONTRO NACIONAL DA ASSOCIAÇÃO DOS PROGRAMAS DE PÓS-GRADUAÇÃO EM ADMINISTRAÇÃO, 31, 2007, Rio de Janeiro. Anais... Rio de Janeiro, ANPAD, 2007. 1 CD. 